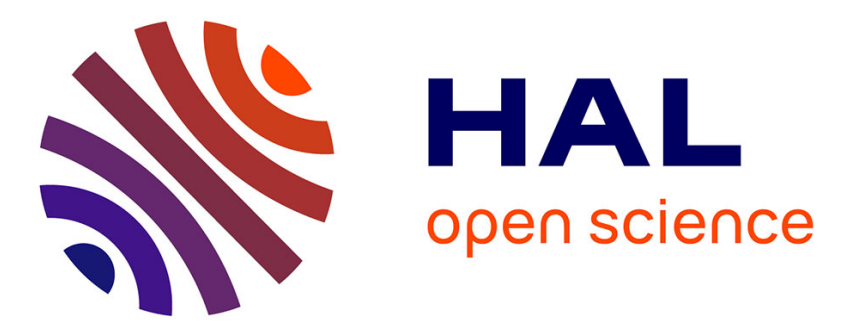

\title{
Mapping of muscle deformation during heating: in situ dynamic MRI and nonlinear registration
}

Mustapha Bouhrara, Benoît B. Lehallier, Sylvie Clerjon, Jean-Louis Damez, J.-M. Bonny

\section{> To cite this version:}

Mustapha Bouhrara, Benoît B. Lehallier, Sylvie Clerjon, Jean-Louis Damez, J.-M. Bonny. Mapping of muscle deformation during heating: in situ dynamic MRI and nonlinear registration. Magnetic Resonance Imaging, 2012, 30 (3), pp.422-430. 10.1016/j.mri.2011.10.002 . hal-02645836

\section{HAL Id: hal-02645836 \\ https://hal.inrae.fr/hal-02645836}

Submitted on 29 May 2020

HAL is a multi-disciplinary open access archive for the deposit and dissemination of scientific research documents, whether they are published or not. The documents may come from teaching and research institutions in France or abroad, or from public or private research centers.
L'archive ouverte pluridisciplinaire HAL, est destinée au dépôt et à la diffusion de documents scientifiques de niveau recherche, publiés ou non, émanant des établissements d'enseignement et de recherche français ou étrangers, des laboratoires publics ou privés. 


\title{
Mapping of muscle deformation during heating: in situ dynamic MRI and nonlinear registration
}

\author{
Mustapha Bouhrara, Benoist Lehallier, Sylvie Clerjon, Jean-Louis Damez, Jean-Marie Bonny* \\ UR370 QuaPA, INRA, F-63122 Saint-Genès-Champanelle, France \\ Received 25 March 2011; revised 23 September 2011; accepted 6 October 2011
}

\begin{abstract}
We present developments in dynamic magnetic resonance imaging that allow internal structural muscle markers to be followed during heating. This monitoring is based on quantitative characterization of the experimental conditions and their temperature time course. A nonlinear image registration technique was optimized and applied to consecutively acquired images to measure the deformation fields in the muscle. A model coupling local deformation and temperature was obtained, which for the first time takes into account the variations of deformation and temperature in the sample. This modeling opens the way to a better understanding of the mechanisms responsible for mass loss and degradation of the textural properties of muscle during heating.
\end{abstract}

(C) 2012 Elsevier Inc. All rights reserved.

Keywords: Dynamic MRI; Deformation fields; Muscle; Meat; Heating; Temperature; Nonlinear registration

\section{Introduction}

Agrofood products, particularly meat, are most often consumed cooked. Predicting the effects cooking has on the sensory, nutritional and technological qualities of the consumed product is of major importance for both the consumer and the meat industry. To date, there is no reliable model linking the deformation of the muscle with the heating profile applied to it. However, such a model is necessary for the simultaneous control of mass loss and degradation of the textural properties of cooked food.

Analysis of the coupling between deformation and temperature is affected by (a) the deformation measurement methods, which are mostly nonlocal and (or) destructive [1], and (b) the assumption of a homogeneous temperature inside the sample [2]. To build more precise models, i.e., that take account of the variations of deformation and temperature in the sample, it is clearly advisable to measure deformation and temperature simultaneously and at the same location.

Imaging in general and magnetic resonance imaging (MRI) in particular will highlight structural meat markers at a

* Corresponding author. Tel.: +334 736241 52; fax: +334 73624089 .

E-mail address: jean-marie.bonny@clermont.inra.fr (J.-M. Bonny). mesoscopic scale [3-6]. In a recent work [7], we showed the feasibility of in situ MRI of muscle during a thermal process by canceling signal of circulating heating water using a bipolar gradient in the three directions. This cancelation allows reducing field of view (FOV) and then improving spatial resolution. We also showed that $T_{2}{ }^{*}$-weighted MR images sustained a sufficient contrast between internal markers of the connective network and muscle fibers throughout the temperature range $\left(20^{\circ} \mathrm{C}-75^{\circ} \mathrm{C}\right)$. These recent results have paved the way for the two main objectives of the present manuscript. The first is to estimate deformation fields by monitoring the displacement of these fiducial markers inside images of muscle during heating. The second is to interpret the mechanisms underlying muscle contraction on the basis of the relationship between temperature and deformation.

This paper is organized as follows. The first subsection presents our experimental procedure. The next subsections describe in detail the approach for optimizing image acquisition protocol. It was based on different experiments for measuring the factors which significantly influence image quality and which were likely to evolve during heating. The next part deals with the estimation of deformation fields from a dynamic set of MR images and especially how the registration procedures, required for 
deformation field reconstruction, have been validated. Finally, an experimental model linking temperature and deformation is introduced and discussed.

\section{Materials and methods}

\subsection{Samples and hardware}

The samples come from biceps femoris bovine muscle, the connective network of which is elastin rich. They were cut in the form of cylinders $5 \mathrm{~cm}$ in diameter by $6 \mathrm{~cm}$ in length with the muscle fibers oriented axially. The meat cylinders were then placed in plastic bags in a vacuum to prevent direct contact with the circulating heating water. Each sample was heated over the temperature range $20^{\circ} \mathrm{C}-$ $75^{\circ} \mathrm{C}$ using circulating water $(42 \mathrm{~L} / \mathrm{min})$ in a magnetic environment-compatible device. This device comprised a watertight sample holder cell made of polyetheretherketone which was placed inside a sleeve made of Teflon for ensuring thermal insulation between the cell and the radiofrequency (RF) coil. The regulation system was programmed so that the temperature of the water rose constantly at a climb rate of $0.74^{\circ} \mathrm{C} / \mathrm{min}$. The experiment is described in more detail in Ref. [7].

Image acquisition was carried out using a Biospec horizontal 4.7 T MRI system (Bruker GmbH, Ettlingen, Germany), of diameter $26 \mathrm{~cm}$, equipped with a BGA-26 rapid gradient system (maximum amplitude $50 \mathrm{mT} \mathrm{m}^{-1}$, rise time $260 \mu \mathrm{s})$. The transmit-receive RF coil was a linear birdcage. The main fiber axis in the sample was placed approximately parallel to the main direction of the static magnetic field $B_{0}$ of the magnet. All MR acquisitions were performed in the transverse plane which intercepted the muscle fiber axis perpendicularly. The heating water run-off was roughly directed by the pump parallel to these muscle fascicles.

\subsection{Measurement of muscle nuclear magnetic resonance (NMR) properties during heating}

The temperature rise induced changes in intrinsic NMR sample parameters. $T_{1}, T_{2}$ relaxation times and proton density (PD) were mapped according to the temperature from three images successively acquired using a single spin-echo sequence [8] [i.e., two images at different repetition times (TRs) for $T_{1}: \mathrm{TR}_{1} / \mathrm{TR}_{2}=1000 / 5000 \mathrm{~ms}$ at the fixed echo time (TE) $=7.2 \mathrm{~ms}$; and two images at different TEs for $T_{2}$ and PD: $\mathrm{TE}_{1} / \mathrm{TE}_{2}=7.2 / 37.2 \mathrm{~ms}$ and at the fixed $\mathrm{TR}=5000 \mathrm{~ms}$ ]. Shimming, tuning and flip angle calibration procedures were carried out at each temperature step in order to minimize estimation errors due to instrumental shifts due to temperature changes. All the images were obtained with an FOV of $128 \times 128 \mathrm{~mm}^{2}$, a matrix of $32 \times 32$ voxels and thickness $10 \mathrm{~mm}$ (volume of a resulting voxel $4 \times 4 \times 10$ $\mathrm{mm}^{3}$ ). Parametric maps were reconstructed from the ratio of image pairs assuming a monoexponential behavior of both $T_{1}$ and $T_{2}$ relaxation curves. The chemical shift was measured by Point-RESolved Spectroscopy for localized spectroscopy in a single voxel, centered in the sample and of volume $4 \times 4 \times 6 \mathrm{~mm}^{3}$. These measurements were taken at constant step temperatures $10^{\circ} \mathrm{C}$ apart.

\subsection{Assessment of instrumental shifts during heating}

In addition to the time course of the physical properties of the sample, the increase in the temperature caused a linear drift of the frequency tuning and impedance matching of the $\mathrm{RF}$ coil, which were optimized at the beginning of the experiment at $20^{\circ} \mathrm{C}$. This degradation was induced by a continuous variation of the coupling between the RF coil and the sample due to (a) the deformation of the sample starting from $\sim 42^{\circ} \mathrm{C}[7,9]$ and (b) the variations in the dielectric properties of the muscle from $60^{\circ} \mathrm{C}$ (i.e., dielectric permittivity and dielectric loss factor [10]). To measure the degradation of the signal-to-noise ratio (SNR) due to this drift during a typical heating ramp of $0.74^{\circ} \mathrm{C} / \mathrm{min}$, SNRs of steady-state free precession (SSFP) images were measured at $75^{\circ} \mathrm{C}$ without and after retuning/matching of the loaded coil.

\subsection{Flow mapping of circulating heating water}

Velocity measurement of the heating water at the interfaces of the sample was necessary to calculate the heat exchange coefficient between water and sample. This coefficient is an essential boundary condition to numerically simulate the spatiotemporal distribution of temperature in the muscle [7]. Also, the characterization of water run-off speed, and in particular the gradient in the tank, is useful for controlling the conditions of the experiment and helping to interpret the residual motion artifacts appearing in the images.

A phase-contrast flow imaging method [11] was thus used to map the water run-offs in the tank. It consisted of acquiring a reference image and three other velocity-encoded images from which the phase difference led to velocity assessment in read, phase and slice spatial-encoding directions (i.e., $V_{\text {read }}, V_{\text {phase }}$ and $V_{\text {slice, }}$ respectively). The velocity magnitude was then computed from the three

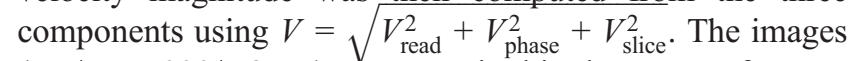
$(\mathrm{TR} / \mathrm{TE}=5000 / 5.8 \mathrm{~ms})$ were acquired in the center of a zone comprising the tank and the sample, with a flow range from $-50 \mathrm{~cm} / \mathrm{s}$ to $+50 \mathrm{~cm} / \mathrm{s}$, an FOV of $128 \times 128 \mathrm{~mm}^{2}$, a matrix of $64 \times 64$ voxels and a slice thickness of $4 \mathrm{~mm}$ (volume of the resulting voxel $2 \times 2 \times 4 \mathrm{~mm}^{3}$ ).

The temporal resolution $\left(21^{\prime} 20^{\prime \prime}\right)$ of this protocol was too slow to make dynamic measurements during the heating. The speed of water in the tank was thus mapped at the extreme temperatures (i.e., $20^{\circ} \mathrm{C}$ and $75^{\circ} \mathrm{C}$ ) by holding the temperature constant during the two acquisitions.

\subsection{Suppression of the heating water signal}

Uninterrupted water circulation during the experiment was essential to control the transfer of heat from the water to the sample. The NMR signal of circulating water thus had to be suppressed to obtain images of the muscle sample 
highlighting the internal fiducial markers. The solution adopted was to equip the sequences with bipolar gradients (BGs) which allowed the signal of the mobile protons to be attenuated proportionally to their velocity [12].

The high amplitude of the water signal (volume of water $\sim 3$ times that of the sample) and its low velocity in certain locations in the tank (cf. section 3.3.) required BGs of strong amplitude (i.e., $90 \%$ of the maximum amplitude of the gradients) for each acquired slice. In practice and despite the cooling of the gradients by water, the BGs generated an overheating of the gradient coil during multislice acquisitions, which threatened to damage the gradient coil and, by thermal conduction, the transmit-receive coil, which is in close contact. Accordingly, we used BGs of sinusoidal shape, which significantly reduced this overheating compared with the trapezoidal shape.
To determine the best direction and the minimal duration of the BGs that would ensure adequate suppression of the signal due to circulating water throughout the experiment, projections of the signal coming from the tank (i.e., from both sample and heating water) were measured for each of the three directions and varying the duration of the BGs $(0.5$ to $7 \mathrm{~ms}$ in $0.1 \mathrm{~ms}$ steps, amplitude $45 \mathrm{mT} \mathrm{m}^{-1}$ ) and the temperature (constant temperatures in steps of $10^{\circ} \mathrm{C}$ ). During a measure in a given direction, the BGs were maintained with $7 \mathrm{~ms}$ and $45 \mathrm{mT} \mathrm{m}^{-1}$ in the other two directions. The profiles were obtained with an SSFP sequence with a single echo (TR/TE $=2000 / 18 \mathrm{~ms}$ ) without phase encoding (which thus becomes the direction of projection, cf. Fig. 1A), an FOV of $64 \times 64 \mathrm{~mm}^{2}$ sampled on 128 points and a slice thickness of $2 \mathrm{~mm}$ (voxel volume of the resulting profile $=0.5 \times 64 \times 2 \mathrm{~mm}^{3}$ ). To validate the effectiveness of the suppression for the whole

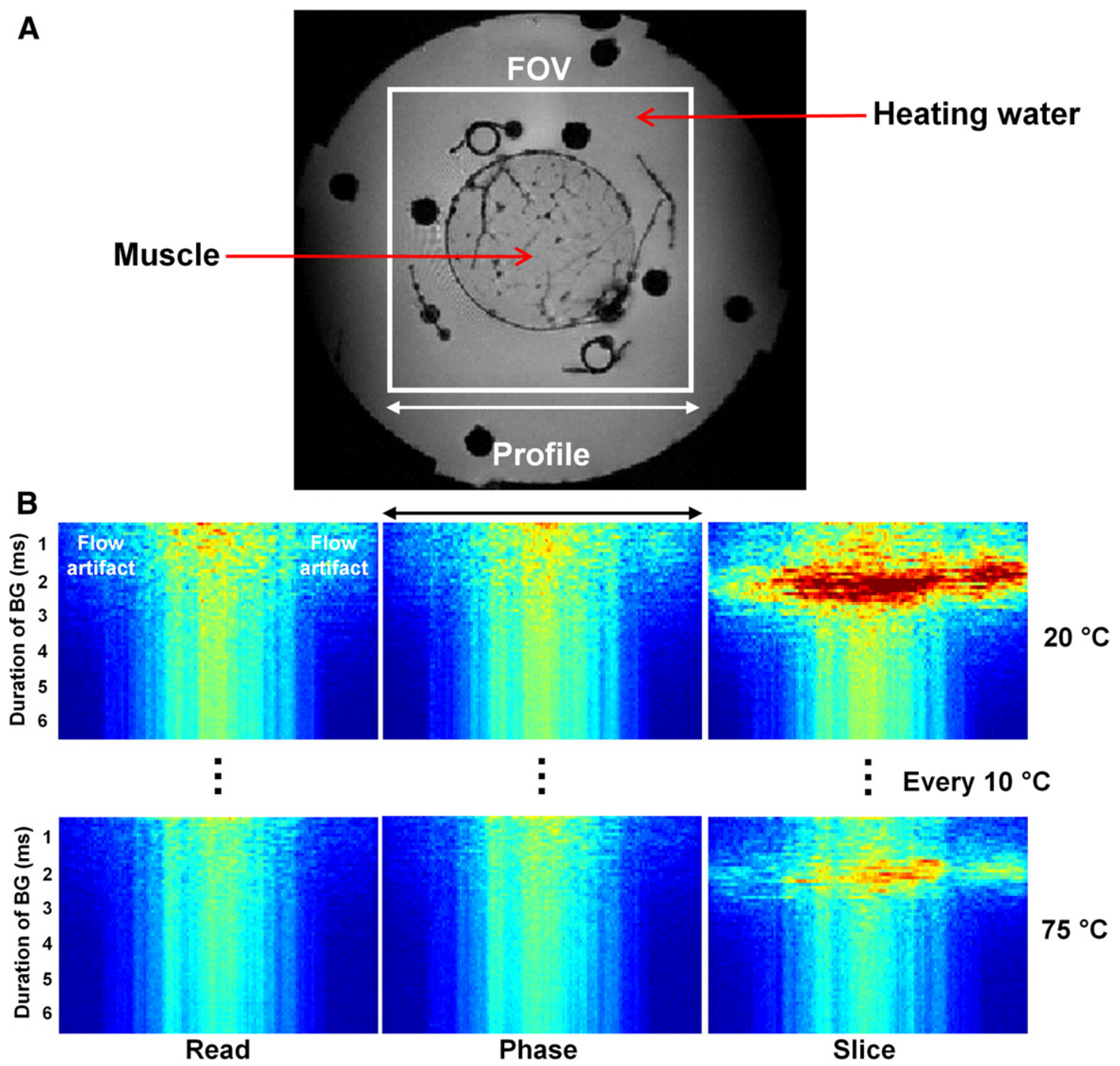

Fig. 1. (A) Orientation and size of the profile for the sample tank. (B) Effect of BG duration on the cancellation of the heating water signal assessed by measuring the profile of the signal from the whole tank. The duration of the BG varies only in the specified direction, BG being applied in the other two directions for 7 ms at $45 \mathrm{mT} \mathrm{m}^{-1}$. The windowing of color levels was adjusted at each temperature to compensate for the continuous SNR loss. 
sample, we measured these projections in ten $2 \mathrm{~mm}$ spaced planes transverse to the sample.

\subsection{Image acquisition}

A dynamic imaging experiment consisted in acquiring $T_{2}{ }^{*}$-weighted images using a single echo SSFP sequence with sinusoidal BGs. A set of 20 acquisitions was continuously obtained during the temperature rise of heating water between $20^{\circ} \mathrm{C}$ and $75^{\circ} \mathrm{C}$. For each acquisition, six transverse noncontiguous sections of the sample (interslice distance $4 \mathrm{~mm}$ ) were obtained with an FOV of $64 \times 64 \mathrm{~mm}^{2}$, a matrix of $128 \times 128$ voxels and a thickness of $2 \mathrm{~mm}$; the voxel volume was $0.5 \times 0.5 \times 2 \mathrm{~mm}^{3}$ (temporal resolution $4^{\prime} 16^{\prime \prime}$, $\mathrm{TR}=2000 \mathrm{~ms}$ ). The deformation fields of the sample could be obtained by spatial registration of two successively acquired images [13]. The geometrical transformation that minimizes the difference between these two images is an estimate of the deformation to be applied to switch from the initial image to the final image. During the heating from $20^{\circ} \mathrm{C}$ to $75^{\circ} \mathrm{C}$, preliminary experiments showed that the deformation in the longitudinal direction of the sample was negligible (less than $3 \%$ in length). By contrast, it was marked in the transverse plane (35\% of the surface), and it was anisotropic. The measurement of the deformation fields thus required a nonlinear registration, limited to the two dimensions of the images obtained in this transverse plane.

\subsection{Image registration}

An automated image registration package [14,15] was chosen to perform this nonlinear image registration because (a) it is available to the research community free of charge (http:// bishopw.loni.ucla.edu/air5/), (b) it allows many degrees of freedom (DOFs) for performing nonlinear deformations and (c) it is efficient compared with the other algorithms [16-19]. Nonlinear deformation models have been compared by increasing the DOF of the polynomial warping. To compare these various models quantitatively, several pairs of landmarks were manually positioned on three different slices (Fig. 2) obtained at $20^{\circ} \mathrm{C}$ (reslice image) and $75^{\circ} \mathrm{C}$ (target image). These pairs of internal markers were characteristic points of the connective network, visible in hyposignal on MR images. We elected to evaluate the accuracy of registration on the two images acquired at the extreme temperatures rather than on two consecutive acquisitions in order to test the nonlinear models on widely different amplitudes of deformation. The registration error (i.e., deformation estimate) was estimated by calculating, after the registration, the Euclidian distance between two homologous landmarks.

Suppressing the elements of no interest increases the accuracy and robustness of image registration [20,21]; thus, a slice-by-slice manual segmentation of the muscle was always carried out before registration.

\subsection{Measurement of deformation fields}

Each slice of the image $I\left(t_{i-1}\right)$, obtained at temperature $t_{i-1}$, was registered on its corresponding slice of $I\left(t_{i}\right)$. For this purpose, we used the two-dimensional (2D) deformation model presenting the minimum average error of registration (i.e., fourth order, see previous subsection). All parameters of the model being known after registration, the

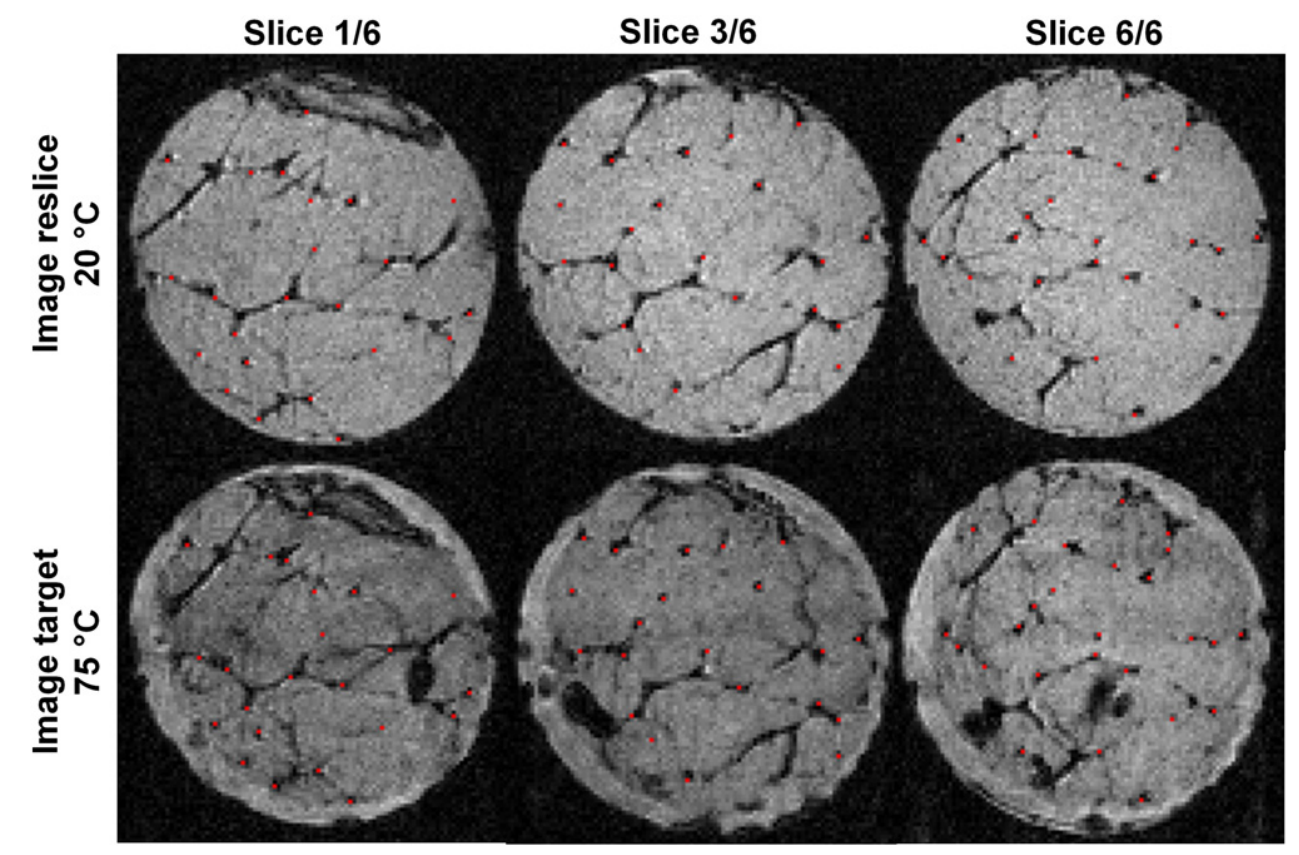

Fig. 2. MR images obtained at $20^{\circ} \mathrm{C}$ and $75^{\circ} \mathrm{C}$ showing internal fiduciary markers and the positions of the pairs of landmarks (red points). Landmarks (number of landmarks=23, 21 and 26, respectively, for sections 1,3 and 6) were positioned manually on the images and used to optimize the 2D nonlinear deformation model. 
deformation field $\mathbf{w}\left(t_{i}\right)$ was inferred by computing the two components of $2 \mathrm{D}$ displacement in each voxel position of the image. This procedure was iterated for each successive pair of the image sequence.

\subsection{Deformation and temperature modeling}

Each voxel of the image obtained at $20^{\circ} \mathrm{C}$ was tracked by successively applying the transformation given by $\mathbf{w}\left(t_{i}\right)$. This monitoring thus allows deformation and temperature to be recorded at the same time for each voxel. Lastly, the deformation is averaged over all the voxels in the slice for a given temperature.

\section{Results}

\subsection{Changes of muscle NMR properties during heating}

Fig. 3 presents the time courses of $T_{1}, T_{2}$ and PD with temperature, each point showing mean and standard deviation computed over all voxels belonging to the muscle.
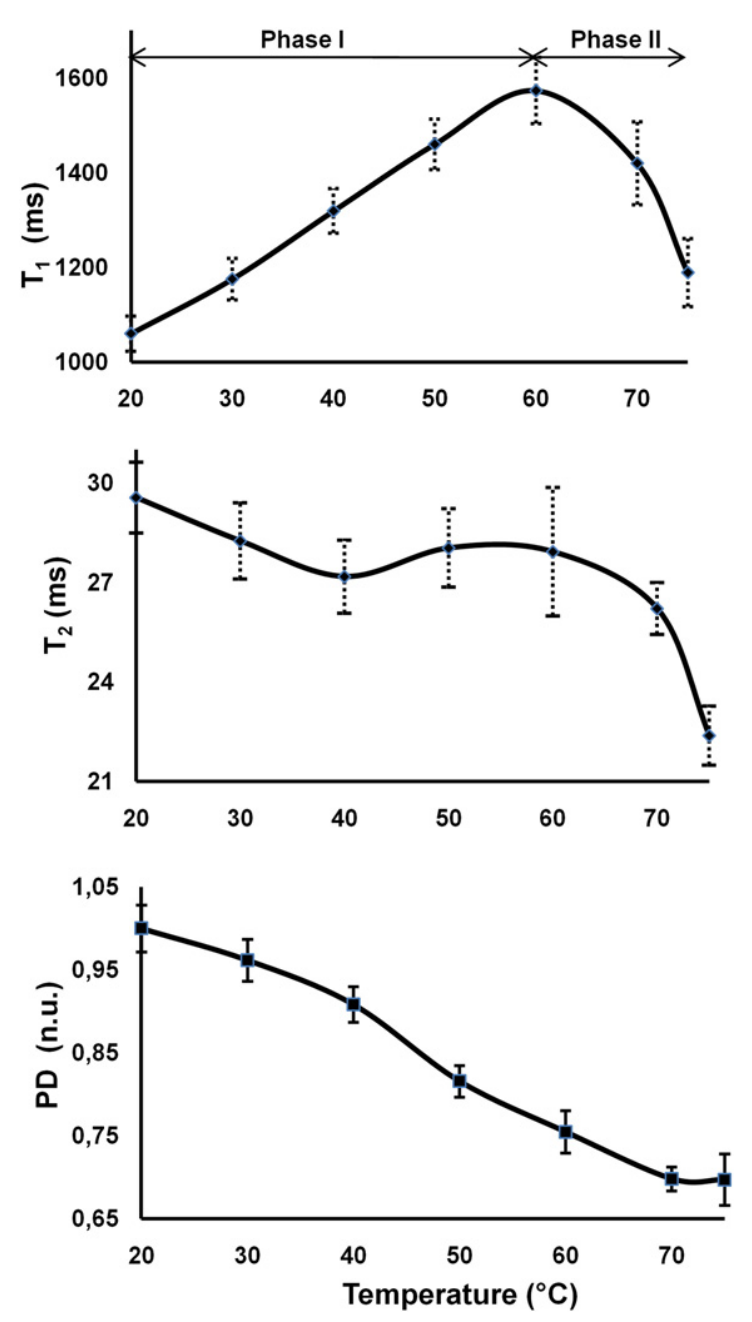

Fig. 3. Time courses of $T_{1}$ and $T_{2}$ relaxation times and of PD with muscle temperature.
Between $20^{\circ} \mathrm{C}$ and $75^{\circ} \mathrm{C}$, the combined action of temperature (i.e., obeying Boltzmann distribution, PD changes by approximately $0.29 \% /{ }^{\circ} \mathrm{C}$ in our temperature range [22]) and water transfers in the muscle led to an average decrease of $31 \%$ in PD, a decrease from 29 to $22 \mathrm{~ms}$ in main $T_{2}$ and an increase from 1050 to $1200 \mathrm{~ms}$ in $T_{1}$ (crossing a peak of $1600 \mathrm{~ms}$ at $\sim 60^{\circ} \mathrm{C}$ ). The total SNR loss generated by these physicochemical properties variations in muscle was $\sim 40 \%$.

\subsection{Instrumental shifts during heating}

The quality factor of the loaded coil was almost unchanged (decrease of $3 \%$ ) between the beginning and end of heating. However, the resonance frequency of the coil $\omega_{\mathrm{c}}$ and its impedance at this frequency $Z\left(\omega_{\mathrm{c}}\right)$ varied, respectively, by $254 \mathrm{kHz}$ and $24 \%$. The proton chemical shift with temperature was $-0.0148 \mathrm{ppm} /{ }^{\circ} \mathrm{C}$, in agreement with the literature value [23]. An increase of $55^{\circ} \mathrm{C}$ led to a chemical shift of $160 \mathrm{~Hz}$, still low considering the voxel bandwidth used $(390 \mathrm{~Hz} /$ voxel), and therefore generated small chemical shift artifacts. In addition, the ${ }^{1} \mathrm{H}$ peak broadened due to the deformation of the sample which degraded the homogeneity of the magnetic field in the sample from the initial shimming conditions. The total SNR loss caused by these extrinsic variations was $\sim 15 \%$. In all, our measurements show that the total loss in SNR was $\sim 55 \%$ between $20^{\circ} \mathrm{C}$ and $75^{\circ} \mathrm{C}$. The dominant causes of this decline were variations in the physical and chemical parameters of the muscle $(\sim 40 \%)$, the remaining $\sim 15 \%$ being due to the changes in the coil/sample matching and the increase in temperature-dependent noise made by the sample.

\subsection{Mapping of the heating water velocity}

Apart from the areas with zero velocity corresponding to the presence of obstacles and air gap to water circulation in the tank, mapping of the velocity magnitude measured by MRI showed (a) that the distribution of the heating water velocity was not homogeneous in the tank (Fig. 4) and (b) that velocity average decreased by $23 \%$ between the beginning and the end of the experiment. The range of velocity measured from this mapping at the borders of the sample lay between 3 and $45 \mathrm{~cm} / \mathrm{s}$. In this range, numerical simulations showed that the thermal transfer varied narrowly. The thermal and spatial distribution could therefore be obtained by numerical simulation with a low dependence on the boundary conditions [7].

\subsection{Suppression of the heating water signal}

Fig. 1B gives the average of projections in 10 noncontiguous slices for each of the three directions of BG application. The artifacts produced by the circulating water predominated in the slice direction because this was the principal direction of flow. Nevertheless, the signal of circulating water decreased with the duration of the BG for the three directions. To maximize image SNR, the quantitative analysis of these profiles showed that it was 
$20^{\circ} \mathrm{C}$

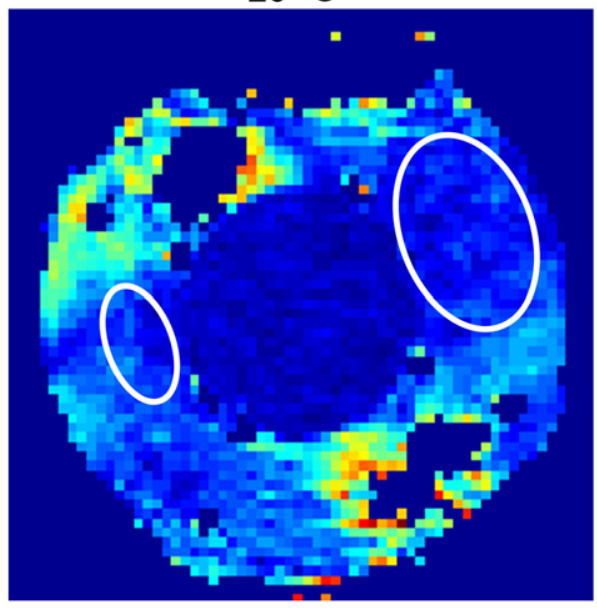

$75^{\circ} \mathrm{C}$

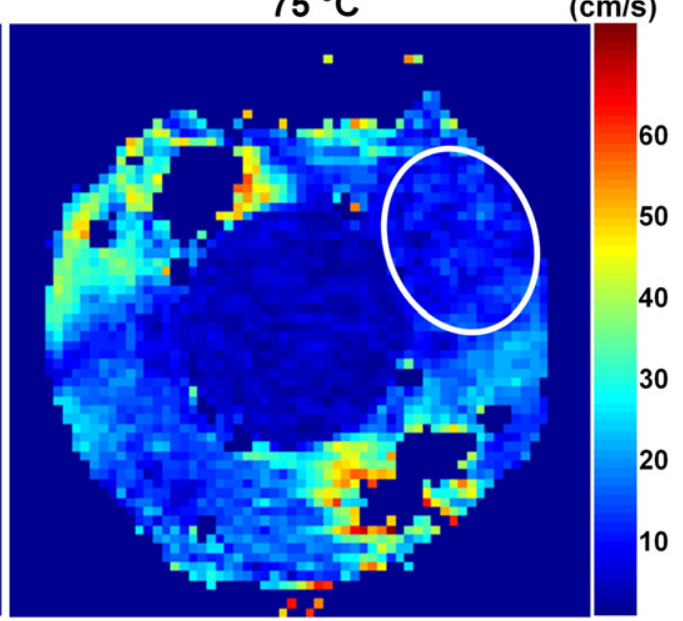

Fig. 4. Distribution of the magnitude of the circulating water velocity in the tank at $20^{\circ} \mathrm{C}$ and $75^{\circ} \mathrm{C}$. Circles define the regions of near stagnation of the heating water.

possible to reduce the $\mathrm{BG}$ duration to $4 \mathrm{~ms}$, the signal coming from the mobile protons of the circulating water with this duration being equivalent to that obtained with duration of $7 \mathrm{~ms}$, for which the suppression was total. At this minimal duration, the resulting TE was $14 \mathrm{~ms}$. With this TE, the contrast between the connective network and muscle fibers was sufficient (Fig. 2). Fig. 4 shows small quasistagnant areas (i.e., hypoflows), which produced light artifacts on images because of the reduced effectiveness of BG at low velocities. Fortunately, these artifacts did not distort the image registration process.

The diffusion weighting ( $b$-value) of the imaging sequence with the BG was very low due to the short delay between the two sinusoidal lobes. The diffusion-related signal attenuation of muscle due to the $\mathrm{BG}$ effect was thus negligible, at both $20^{\circ} \mathrm{C}(1.3 \%)$ and $75^{\circ} \mathrm{C}(2.1 \%)$.

\subsection{Validation of image registration}

Table 1 presents, for each of three slices, the statistical parameters quantifying the error of image registration derived from all landmarks. Registration error did not decrease monotonically with the number of DOFs, but was minimal for the fourth order, as indicated consistently by all the measured criteria (mean, S.D., min and max) in all slices. The fifth-order model led to degradation of the registration, and no change was given by orders higher than the fifth. Higher-order models diverged and led to an overestimation of deformations, especially at the sample borders. The use of higher-order polynomials introduced distortions because the number of supporting points was not sufficient.

\subsection{Deformation fields during heating}

Fig. 5 shows simulated temperature maps, MR images showing fiducial markers inside the muscle and deformation fields (in direction and magnitude) in the central slice during a typical heating experiment. Only the maps corresponding to average temperatures in the muscle in the range $\sim 44^{\circ} \mathrm{C}$ to $\sim 70^{\circ} \mathrm{C}$ are represented, the deformation being negligible outside this range.

\subsection{Deformation and temperature modeling}

Local models linking temperature and deformation obtained by our original approach are given in Fig. 6 for three slices. The standard deviations indicate the disparity of deformations for each temperature in the muscle.

\section{Discussion}

The consequences of heating on both muscle and experimental conditions are difficult to predict. For this reason, several measurements were conducted prior to the in

Table 1

Parameters quantifying the registration error averaged over all pairs of landmarks

\begin{tabular}{lllll}
\hline & 2nd order & 3rd order & 4th order & 5th order \\
\hline Error $(\mathrm{mm})$ & Slice $1 / 6$ & & & \\
Mean & 0.768 & 0.604 & 0.340 & 0.392 \\
S.D. & 0.442 & 0.323 & 0.271 & 0.364 \\
Min & 0.251 & 0.186 & 0.009 & 0.026 \\
Max & 1.597 & 1.015 & 0.803 & 1.202 \\
& Slice 3/6 & & & \\
Mean & 0.913 & 0.536 & 0.405 & 0.443 \\
S.D. & 0.563 & 0.503 & 0.327 & 0.390 \\
Min & 0.147 & 0.048 & 0.003 & 0.050 \\
Max & 1.999 & 1.781 & 1.007 & 1.260 \\
& Slice 6/6 & & & \\
Mean & 1.138 & 0.682 & 0.601 & 0.599 \\
S.D. & 0.671 & 0.524 & 0.507 & 0.615 \\
Min & 0.134 & 0.036 & 0.024 & 0.034 \\
Max & 2.207 & 2.115 & 2.042 & 2.503 \\
\hline
\end{tabular}

Results are represented for four nonlinear models with increasing DOFs and for three different slices. 

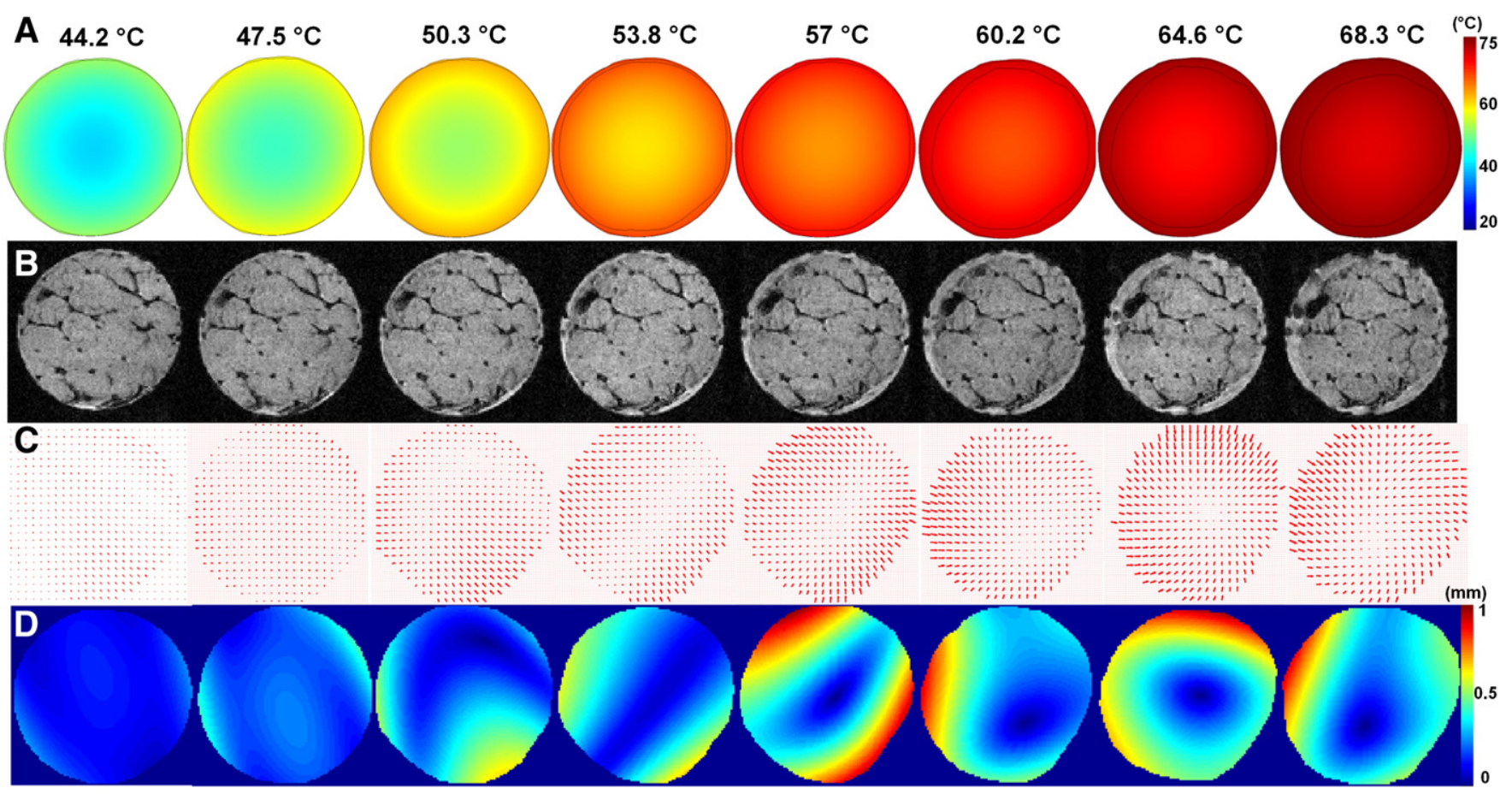

Fig. 5. For eight average temperatures in the sample: (A) temperature maps obtained by numerical simulation and (B) the corresponding NMR $T_{2} *$-weighted images. The windowing of gray levels was adjusted for each image to compensate for the continuous SNR loss. (C-D) Representations, in direction and magnitude, of deformation field $\mathbf{w}$.

situ experiments devoted to deformation assessment in order to optimize their imaging conditions. Those concerning the impact of heating on relaxation properties and PD of muscle assumed monoexponential behavior of decays. It seems reasonable if one refers to a previous NMR relaxation study in meat which revealed during cooking a merging of small $T_{2}$-components into a persistent bulk peak [9], the latter corresponding to the one measured by imaging. Despite a slight $T_{1}$ underestimation of less than $\sim 5 \%$ due to an insufficient TR length, the changes of muscle NMR properties during heating highlight two main phases (Fig. 3): during phase I (i.e., up to $\sim 60^{\circ} \mathrm{C}$ in the sample),
$T_{1}$ increased because of the decrease of the correlation time $\tau_{\mathrm{c}}$ between water molecules with temperature, which increases the rate of dipole-dipole interactions [24]. This increase was similar to that observed at $63 \mathrm{MHz}$ in a more restricted temperature range [25]. According to Nelson and Tung [26], $T_{2}$ varies little with temperature in this phase. During phase II, the water expulsion outside the sample due to the contraction of the muscle with heat produces a marked decrease in the PD. The elevation of the resulting protein concentration induces stronger interactions between these macromolecules and residual water and thus explains the simultaneous decrease of $T_{1}$ and $T_{2}$. Quantitatively, the
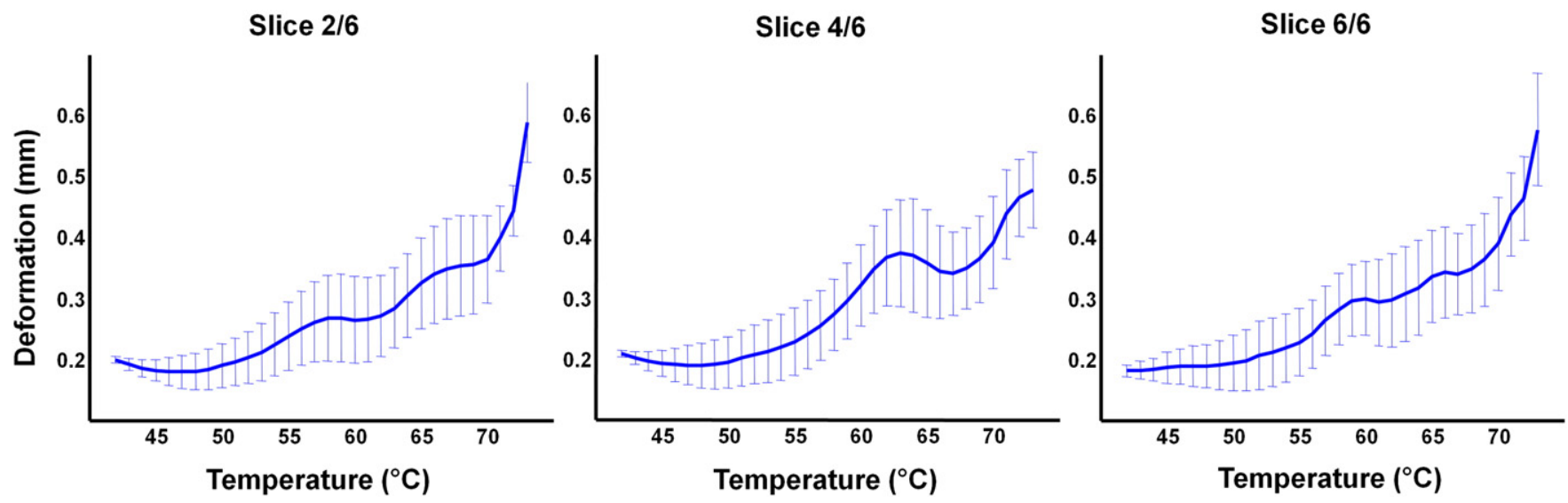

Fig. 6. Time course of muscle deformation magnitude with temperature. 
physicochemical properties of muscle therefore evolve with heating, all adversely affecting the SNR.

Instrumental shifts due to heating also affect SNR. Because there was no automatic tuning and matching system, the correction of these degradations had to be done manually during the experiment. We opted to tolerate this loss to maintain a continuous acquisition of $T_{2}{ }^{*}$-weighted images, the tuning and matching of the loaded coil being optimized only at the beginning of the experiments at $20^{\circ} \mathrm{C}$.

At $4.7 \mathrm{~T}$ and for an internal diameter of the coil twice the diameter of the tank, thermal noise produced by the tank was dominant compared with that due to the coil $[27,28]$. Image noise therefore increased with the temperature of the water and of the sample in the tank. Under these conditions, the image noise depended only slightly on the quality factor of the coil. Thus, our transmit-receive RF birdcage coil with linear polarization was proven to be an appropriate choice.

The decrease of heating water average velocity measured by flow mapping is counterintuitive since an increase in the velocity could be expected due to a decrease in water viscosity with temperature. Estimation of Reynolds number shows that the flow in the tank is far beyond the transitional regime between laminar and turbulent regimes. In addition, turbulences are caused by various obstacles present in the tank (e.g., the sample itself and the tank walls). Therefore, the flow is turbulent in our whole range of temperatures. Such regime leads to inhomogeneous intravoxel velocity distribution for which the mean intravoxel phase is not proportional to the mean velocity, and then biases velocity estimation using phase-encoded MR maps. To summarize, the found decrease in heating water velocity may be due to the underestimation inherent to the mapping method and changes of flow distribution due to the decrease in water viscosity with temperature. Besides, a decrease in the pump effectiveness with temperature cannot be excluded. Inhomogeneous intravoxel velocity distribution due to turbulent regime also explains why $\mathrm{BG}$ attenuates the signal of flowing heating water in the three directions (Fig. 1B) and why they had to be applied simultaneously along these three directions during acquisition of flow-suppressed $T_{2}{ }^{*}$ weighted images. As a precaution, the measured decrease of $23 \%$ in the heating water average velocity should have required increasing the efficiency of the suppression pattern with temperature. This was not necessary because, simultaneously with the deceleration, the hot water signal decreased strongly (from $\sim 55 \%$ between $20^{\circ} \mathrm{C}$ and $75^{\circ} \mathrm{C}$ ) owing to the concomitant increases in temperature diffusion coefficient $[29,30]$ and $T_{1}$ and decrease in $T_{2}$.

Temperature maps and $T_{2}{ }^{*}$-weighted images, respectively, show spatial heterogeneity in temperature (Fig. 5A) and a sufficient image quality to locate internal fiducial markers despite the continuous loss of SNR (Fig. 5B). Mass transfers are observable which correspond to water exudation in the interfascicular spaces and outside muscle. They are discussed in detail in Ref. [7]. Deformation fields in the muscle (Fig. 5C, D) changed with time and were spatially heterogeneous. This result experimentally validates the utility of imaging for temporal and spatial coupling of temperature and deformation. This deformation was greater at the surface than at the center of the sample because of the facilitated heat exchange on the sample surface. There was a process of contraction of the muscle fibers at the center of the sample causing expulsion of liquid towards the outside of the sample (Fig. 5B). However, we observed that the deformation did not follow the same radial symmetry as the distribution of temperature, emphasizing that other factors determine deformation, in particular, structural factors such as the distribution of the connective network.

Models linking temperature and deformation show similar behaviors (Fig. 6). Local information highlights a moderate strain between $\sim 42^{\circ} \mathrm{C}$ and $\sim 55^{\circ} \mathrm{C}$. This phase corresponds to myosin denaturing and the beginning of the collagen denaturing $[9,31]$ which explain the low observed deformation. Juice transfers take place essentially to interfascicular spaces within the muscle [7]. The deformation accelerated from $\sim 55^{\circ} \mathrm{C}$ due to the temperature effect on both sarcoplasmic proteins, leading to their denaturing and therefore to a reduction of the mechanical resistance of the fibers to compression [32], and collagen inducing contraction of the connective network [33]. Water is then expelled to the outside of the sample [7], which explains the strong observed deformation. Plateaus and the new acceleration of the deformations that occur from $\sim 68^{\circ} \mathrm{C}$ remain difficult to interpret. They could be explained by some other temperature-dependent denaturing $[10,34]$ or by specific mechanisms of internal transfer of juice. This also justifies spatiotemporal monitoring of the water density to interpret the obtained models.

In order to measure the deformation fields, we opted to follow internal markers linked to the muscular structure. Other MRI-based approaches are possible, for example, velocimetry techniques such as that used here to measure the velocity of the circulating water. The latter method is however not well adapted to our context because of its low temporal resolution and the difficulty measuring low velocities. The technique based on tagging could be an option [35], but is better suited to the monitoring of deformations more rapid than those induced by heating in muscle, i.e., those leading to significant displacements during a period corresponding to $T_{1}$ of imaged tissues.

\section{Conclusion}

Developments in dynamic MRI, the quantitative characterization of experimental conditions and the optimization of nonlinear registration enabled us to measure deformation fields in muscle during heating. A first interpretation of the mechanisms involved in muscle contraction with temperature is proposed. It is based on the models developed from local information on deformation and temperature. 
The simple repetition of the experiment on several muscles of the same type will increase the robustness of models. The application of the same experimental approach to different muscle types will help elucidate the influence of structure on deformation during thermal processes and thereby give information on the mass losses and degradation of the textural properties of cooked meat.

\section{Acknowledgments}

This work was funded by the E.U. ProSafeBeef project. MRI experiments were performed at the MR Platform for biological systems at the INRA center of Clermont-Ferrand, France (www.clermont.inra.fr/rmsb/).

\section{References}

[1] Barbera S, Tassone S. Meat cooking shrinkage: Measurement of a new meat quality parameter. Meat Sci 2006;73:467-74.

[2] Micklander E, Peshlov B, Purslow PP, Engelsen SB. NMR-cooking: monitoring the changes in meat during cooking by low-field $1 \mathrm{H}-\mathrm{NMR}$. Trends Food Sci Technol 2002;13:341-6.

[3] Bonny JM, Laurent W, Renou JP. Detection of susceptibility effects using simultaneous $\mathrm{T} 2 *$ and magnetic field mapping. Magn Reson Imaging 2000;18:1125-8.

[4] Bonny JM, Laurent W, Labas R, Taylor R, Berge P, Renou JP. Magnetic resonance imaging of connective tissue: a non-destructive method for characterising muscle structure. J Sci Food Agric 2000;81: $337-41$.

[5] Kohler S, Hiller KH, Waller C, Bauer WR, Haase A, Jakob PM. Investigation of the microstructure of the isolated rat heart: a comparison between $\mathrm{T}_{2}{ }^{*}$ - and diffusion-weighted MRI. Magn Reson Med 2003;50:1144-50.

[6] Kohler S, Hiller KH, Waller C, Jakob PM, Bauer WR, Haase A. Visualization of myocardial microstructure using high-resolution T2* imaging at high magnetic field. Magn Reson Med 2003;49:371-5.

[7] Bouhrara M, Clerjon S, Damez JL, Chevarin C, Portanguen S, Kondjoyan A, et al. Dynamic MRI and thermal simulation to interpret deformation and water transfer in meat during heating. J Agric Food Chem 2011;59:1229-35.

[8] Lee JN, Riederer SJ. Optimum acquisition times of two spin echoes for MR image synthesis. Magn Reson Med 1986;3:634-8.

[9] Bertram HC, Engelsen SB, Busk H, Karlsson AH, Andersen HJ. Water properties during cooking of pork studied by low-field NMR relaxation: effects of curing and the RN-gene. Meat Sci 2004;66:437-46.

[10] Bircan C, Barringer SA. Determination of protein denaturation of muscle foods using the dielectric properties. J Food Sci 2002;67: 202-5.

[11] Pelc NJ, Bernstein MA, Shimakawa A, Glover GH. Encoding strategies for three-direction phase-contrast MR imaging of flow. J Magn Reson Imaging 1991;1:405-13

[12] Pipe JG, Chenevert TL. A progressive gradient moment nulling design technique. Magn Reson Med 1991;19:175-9.

[13] Hellier P, Barillot C, Memin E, Perez P. Hierarchical estimation of a dense deformation field for 3-D robust registration. IEEE Trans Med Imaging 2001;20:388-402.
[14] Woods RP, Grafton ST, Holmes CJ, Cherry SR, Mazziotta JC. Automated image registration: I. General methods and intrasubject, intramodality validation. J Comput Assist Tomogr 1998;22:139-52.

[15] Woods RP, Grafton ST, Watson JDG, Sicotte NL, Mazziotta JC. Automated image registration: II. Intersubject validation of linear and nonlinear models. J Comput Assist Tomogr 1998;22:153-65.

[16] Strother SC, Anderson JR, Xu XL, Liow JS, Bonar DC, Rottenberg DA. Quantitative comparisons of image registration techniques based on high-resolution MRI of the brain. J Comput Assist Tomogr 1994;18:954-62.

[17] West J, Fitzpatrick JM, Wang MY, Dawant BM, Maurer CRJ, Kessler $\mathrm{RM}$, et al. Comparison and evaluation of retrospective intermodality brain image registration techniques. J Comput Assist Tomogr 1997;21: 554-68.

[18] Morgan VL, Pickens DR, Hartmann SL, Price RR. Comparison of functional MRI image realignment tools using a computer-generated phantom. Magn Reson Med 2001;46:510-4.

[19] Klein A, Andersson J, Ardekani BA, Ashburner J, Avants B, Chiang $\mathrm{MC}$, et al. Evaluation of 14 nonlinear deformation algorithms applied to human brain MRI registration. Neuroimage 2009;46:786-802.

[20] Blaffert T, Wiemker R. Comparison of different follow-up lung registration methods with and without segmentation. SPIE Med Imaging 2004;5370:1701-8.

[21] Hajnal JV, Saeed N, Soar EJ, Oatridge A, Young IR, Bydder GM. A registration and interpolation procedure for subvoxel matching of serially acquired MR images. J Comput Assist Tomogr 1995;19: 289-96.

[22] Chen J, Daniel BL, Pauly KB. Investigation of proton density for measuring tissue temperature. J Magn Reson Imaging 2006;23:430-4.

[23] Hindman JC. Proton resonance shift of water in the gas and liquid states. J Chem Phys 1966;44:4582-92.

[24] Bloembergen N, Purcell EM, Pound RV. Relaxation effects in nuclear magnetic resonance absorption. Phys Rev 1948;73:679.

[25] Cline HE, Hynynen K, Hardy CJ, Watkins RD, Schenck JF, Jolesz FA. MR temperature mapping of focused ultrasound surgery. Magn Reson Med 1994;31:628-36.

[26] Nelson TR, Tung SM. Temperature dependence of proton relaxation times in vitro. Magn Reson Imaging 1987;5:189-99.

[27] Darrasse L, Ginefri J-C. Perspectives with cryogenic RF probes in biomedical MRI. Biochimie 2003;85:915-37.

[28] Hoult DI, Lauterbur PC. The sensitivity of the zeugmatographic experiment involving human samples. J Magn Reson 1979;34:425-33.

[29] Le Bihan D, Delannoy J, Levin RL. Temperature mapping with MR imaging of molecular diffusion: application to hyperthermia. Radiology 1989;171:853-7.

[30] Delannoy J, Chen CN, Turner R, Levin RL, Le Bihan D. Noninvasive temperature imaging using diffusion MRI. Magn Reson Med 1991;19: $333-9$

[31] Palka K, Daun H. Changes in texture, cooking losses, and myofibrillar structure of bovine M. semitendinosus during heating. Meat Sci 1999;51:237-43

[32] Wright DJ, Leach IB, Wilding P. Differential scanning calorimetric studies of muscle and its constituent proteins. J Sci Food Agric 1977;28:557-64

[33] Lepetit J. Collagen contribution to meat toughness: theoretical aspects. Meat Sci 2008;80:960-7.

[34] Tornberg E. Effects of heat on meat proteins - implications on structure and quality of meat products. Meat Sci 2005;70:493-508.

[35] Axel L, Dougherty L. MR imaging of motion with spatial modulation of magnetization. Radiology 1989;171:841-5. 